Acta Crystallographica Section C

Crystal Structure

Communications

ISSN 0108-2701

\section{6-Methyl-2-pyridone: an elusive structure finally solved}

\section{Gary S. Nichol and William Clegg*}

School of Natural Sciences - Chemistry, Bedson Building, University of Newcastle upon Tyne, Newcastle upon Tyne NE1 7RU, England

Correspondence e-mail: w.clegg@ncl.ac.uk

\section{Received 7 March 2005}

Accepted 20 April 2005

Online 13 May 2005

The title compound, $\mathrm{C}_{6} \mathrm{H}_{7} \mathrm{NO}$, crystallizes unsolvated from dry toluene after storage for several months at approximately $263 \mathrm{~K}$. Synchrotron radiation was needed in order to carry out data collection because of the small size of the crystals obtained. There are four crystallographically independent molecules in the asymmetric unit. Packing diagrams show that the molecules are linked into infinite chains by hydrogen bonding; two of the four independent molecules link together to form a chain, while the other two molecules form chains involving only their own symmetry equivalents, giving a total of three crystallographically distinct chains in all. The chains are held together by weak $\pi-\pi$ interactions. This structure provides conclusive proof that, in the absence of any other co-crystallized molecule or solvent, the compound exists in the solid state as the pyridone and not the pyridinol tautomer.

\section{Comment}

For many years, 2-pyridone and its 6-substituted derivatives have been widely used as ligands in transition metal coordination chemistry (Rawson \& Winpenny, 1995), and their use in $s$-block metal coordination chemistry is increasing. There is also great interest in the organic compounds themselves, particularly owing to the presence of a keto-enol tautomeric equilibrium, which is observed in the gas phase and in solution. This property has been investigated comprehensively by IR spectroscopy (Gibson et al., 1955; Katritzky et al., 1967; Mason, 1957), UV-visible spectroscopy (Beak et al., 1976), nuclear magnetic resonance spectroscopy (Coburn \& Dudek, 1968) and theoretical calculations (Beak \& Covington, 1978; Beak et al., 1980; Parchment et al., 1991; Wong et al., 1992). Factors influencing this tautomerism include solvent polarity, $\mathrm{pH}$, substituent positions and electronic effects of any substituent. Substituents at the 6-position have the greatest effect; electron-withdrawing substituents are seen to drive the equilibrium towards the pyridinol tautomer, whereas electrondonating substituents favour the pyridone tautomer. For example, 6-chloro-2-hydroxypyridine (Kvick \& Olovsson, 1969) and 6-bromo-2-hydroxypyridine (Kvick, 1976) have electron-withdrawing substituents and both crystallize in the pyridinol form, as predicted by spectroscopic and theoretical studies. By contrast, the unsubstituted molecule crystallizes in the pyridone form (Penfold, 1953).<smiles>Cc1cccc(=O)[nH]1</smiles>

(I)

There is, however, little firm crystallographic evidence to support the theory that an electron-donating substituent, in the absence of any other external influence (e.g. a co-crystallized molecule), will drive the equilibrium towards the pyridone tautomer. Recently, we reported the structure of 6-methyl-2-pyridone as its pentahydrate and we noted then that the only known structures of this molecule were either coordination complexes or co-crystals, with the difficulty in each case of being certain that the structure is pyridone and not pyridinol (Clegg \& Nichol, 2004).

We succeeded, after many attempts, in obtaining crystals of unsolvated 6-methyl-2-pyridone, (I), from a dry toluene solution layered with dry diethyl ether. The crystals resulted as

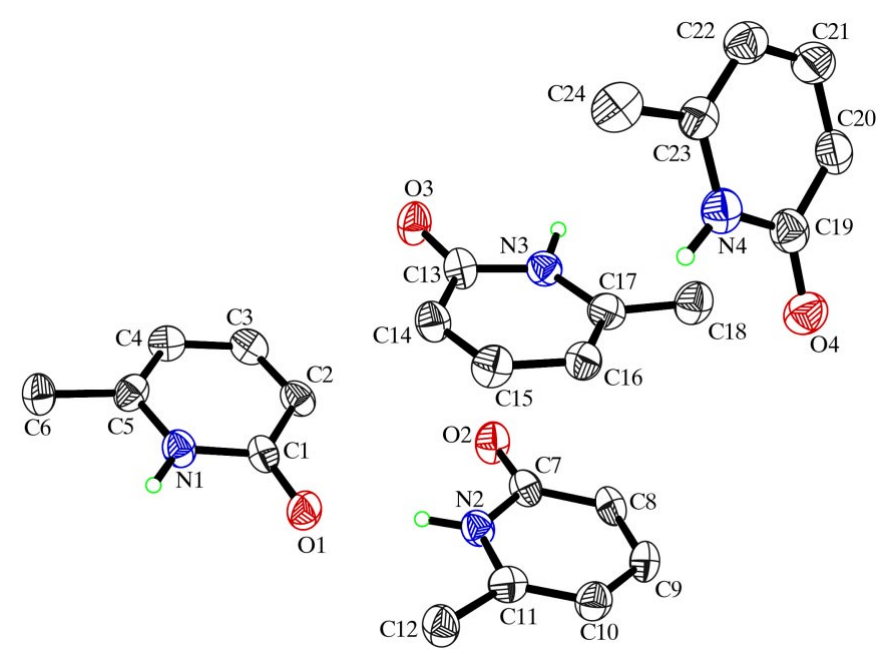

Figure 1

The asymmetric unit of (I), with displacement ellipsoids drawn at the $50 \%$ probability level. $\mathrm{H}$ atoms not involved in hydrogen bonding have been omitted for clarity.

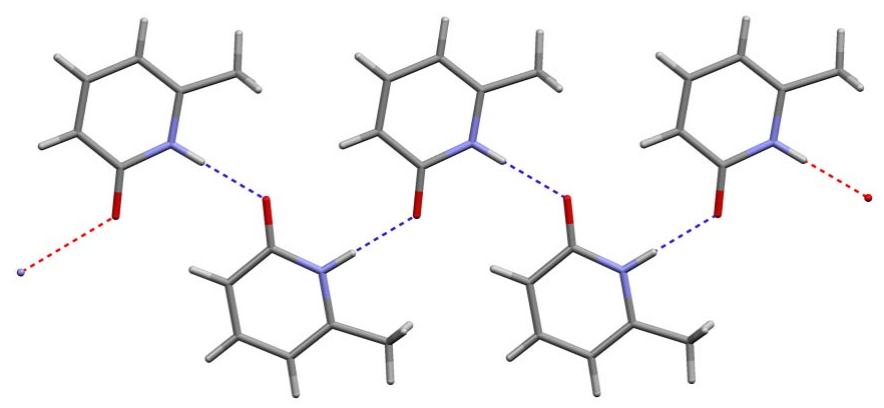

Figure 2

The hydrogen-bonding pattern in (I), forming infinite chains. 
a by-product of a reaction mixture and were grown by storage at approximately $263 \mathrm{~K}$ over a period of several months. The product consisted of large agglomerations of very small single crystals, too weakly diffracting for analysis with standard laboratory X-ray equipment, even with a rotating-anode source, so we used Station 9.8 of the Synchrotron Radiation Source (SRS) at Daresbury Laboratory, Cheshire, England, to carry out data collection.

The asymmetric unit of (I) is presented in Fig. 1. There are four crystallographically independent molecules in the asym-

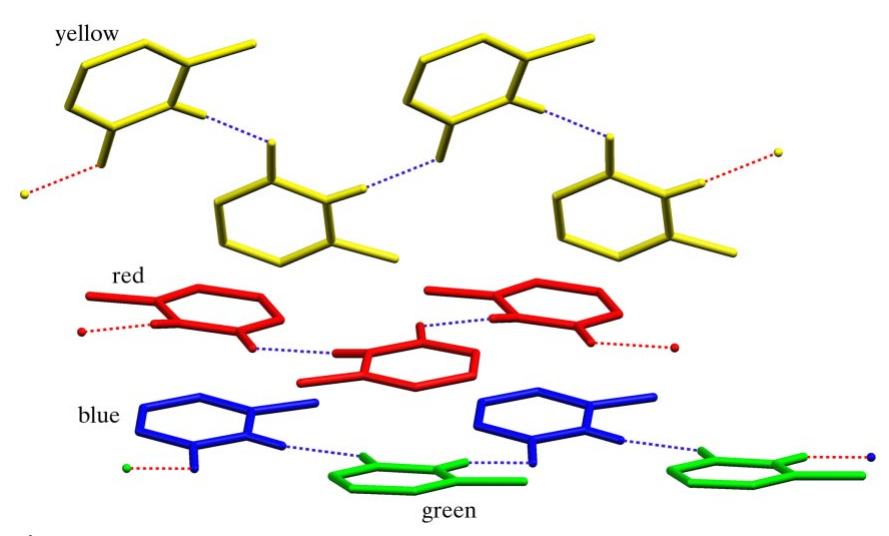

Figure 3

The three different hydrogen-bonded chains. The molecules are coloured in the online version in order to show clearly which molecules form chains with their symmetry equivalents (the yellow top chain and the red middle chain) and which link together (blue and green) to form another chain (the bottom one).

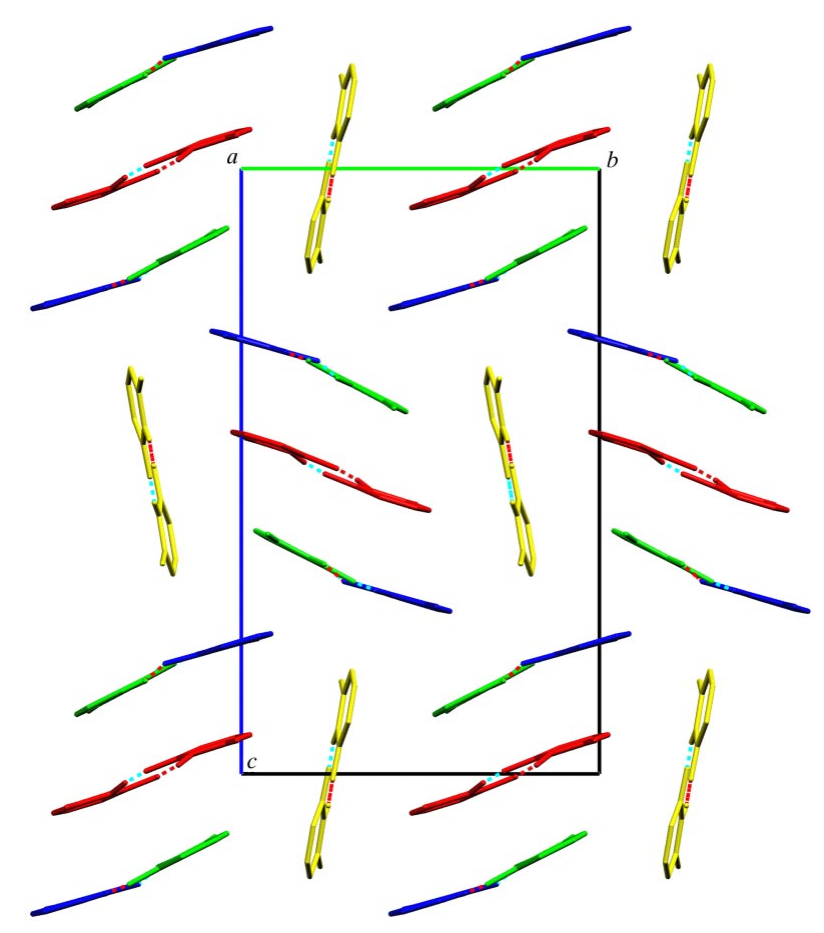

Figure 4

A packing diagram, viewed along the $a$ axis, showing the relative orientation of the three different chains. There are no interchain hydrogen bonds. metric unit; overall $Z=16$. Each molecule is in the pyridone form and has a planar non-H-atom skeleton; the molecular dimensions are unexceptional, apart from the $\mathrm{C}=\mathrm{O}$ bond lengths (Table 1), which are rather long for a carbonyl group of this type but are in general agreement with published lengths (Clegg \& Nichol, 2004). Table 1 also gives geometric data for the atoms of one of the four molecules, and this is representative of the other three. There are differences in the $\mathrm{C}-\mathrm{C}$ bond lengths within the ring, showing that there are distinctly separate localized $\mathrm{C}-\mathrm{N}, \mathrm{C}-\mathrm{C}$ and $\mathrm{C}=\mathrm{C}$ bonds as opposed to a delocalized aromatic ring.

Fig. 2 gives a representation of the hydrogen bonding (Table 2) observed in this structure. The molecules link together to form infinite chains, a motif also observed in the parent 2-pyridone structure but not in the 6-bromo- or 6-chloro-2-hydroxypyridine structures, where instead the molecules dimerize. There are three separate hydrogenbonded chains (formed by different molecules) in this structure (Fig. 3), and these can be seen most easily by colouring each symmetry-independent molecule differently (as shown in the online version of the journal). The 'yellow' and 'red' molecules form separate chains (top and middle) involving only their own symmetry equivalents (i.e. other 'yellow' or 'red' molecules, respectively), whereas the 'blue' and 'green' molecules are linked together alternately to form the third chain (the lowest in Fig. 3). The positions of these three chains relative to one another are clearly seen by viewing along the $a$ axis (Fig. 4).

There is no $\pi-\pi$ stacking between the red chains, as they are displaced from each other by half a unit cell along the $a$ axis, and there is also no $\pi-\pi$ stacking between the blue/green

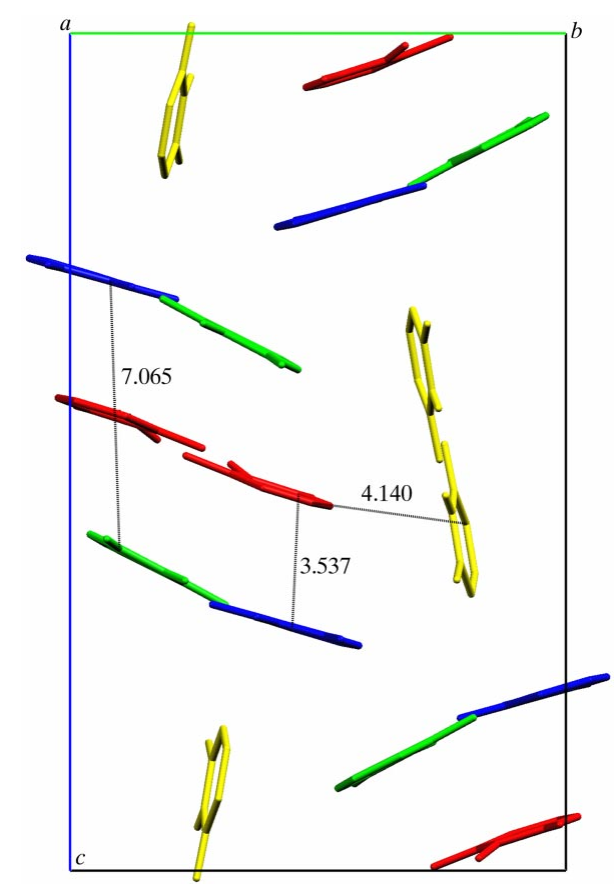

Figure 5

Selected intermolecular distances in $\AA$. 
chains; at around $7 \AA$ they are too far apart. There is a small amount of overlap observed between the red molecule and the blue molecule, and edge-face interactions exist between the red molecule and the yellow molecule. The intermolecular distances are shown in Fig. 5. Given that these weak interactions are the only ones observed of any significance that hold the chains together, it is perhaps not surprising that this compound does not crystallize easily without solvent or another different molecule to encourage hydrogen bonding.

\section{Experimental}

Commercially available 6-methyl-2-pyridone was refluxed with an excess of $\mathrm{CaH}_{2}$ in dry toluene in an attempt to form a calcium complex. After two days, the mixture was filtered and the colourless filtrate was stored at approximately $263 \mathrm{~K}$ for one month. No crystals had formed, so the solution was then layered with diethyl ether and the flask was stored again at approximately $263 \mathrm{~K}$ for a period of around six months, when large clusters of very small crystals were observed. Data were collected at SRS Daresbury via the EPSRC National X-ray Crystallography Service. The crystals redissolved when the flask was stored at room temperature and so no other experimental data (analytical or spectroscopic) could be obtained.

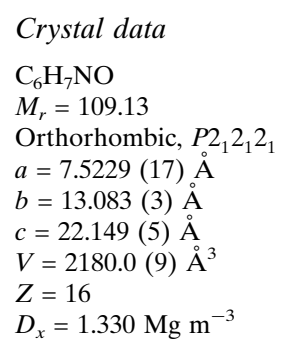

Synchrotron radiation $\lambda=0.6768 \AA$

Cell parameters from 1153 reflections

$\theta=3.0-19.4^{\circ}$

$\mu=0.09 \mathrm{~mm}^{-1}$

$T=120(2) \mathrm{K}$

Needle, colourless

$0.20 \times 0.02 \times 0.01 \mathrm{~mm}$

\section{Data collection}

\section{Bruker APEX-2 CCD}

diffractometer

Thin-slice $\omega$ scans

Absorption correction: multi-scan

(SADABS; Sheldrick, 2003)

$T_{\min }=0.982, T_{\max }=0.999$

16261 measured reflections

\section{Refinement}

Refinement on $F^{2}$

$R\left[F^{2}>2 \sigma\left(F^{2}\right)\right]=0.050$

$w R\left(F^{2}\right)=0.128$

$S=1.05$

2202 reflections

306 parameters

$\mathrm{H}$ atoms treated by a mixture of independent and constrained refinement

Table 1

Selected interatomic distances (̊).

\begin{tabular}{llll}
\hline $\mathrm{O} 1-\mathrm{C} 1$ & $1.270(5)$ & $\mathrm{C} 1-\mathrm{C} 2$ & $1.430(7)$ \\
$\mathrm{O} 2-\mathrm{C} 7$ & $1.263(5)$ & $\mathrm{C} 2-\mathrm{C} 3$ & $1.368(7)$ \\
$\mathrm{O} 3-\mathrm{C} 13$ & $1.268(6)$ & $\mathrm{C} 3-\mathrm{C} 4$ & $1.400(7)$ \\
$\mathrm{O} 4-\mathrm{C} 19$ & $1.247(6)$ & $\mathrm{C} 4-\mathrm{C} 5$ & $1.342(7)$ \\
$\mathrm{N} 1-\mathrm{C} 1$ & $1.372(6)$ & $\mathrm{C} 5-\mathrm{C} 6$ & $1.512(7)$ \\
$\mathrm{N} 1-\mathrm{C} 5$ & $1.371(6)$ & & \\
\hline
\end{tabular}

1474 reflections with $I>2 \sigma(I)$

$R_{\text {int }}=0.128$

$\theta_{\text {max }}=23.7^{\circ}$

$h=-8 \rightarrow 8$

$k=-15 \rightarrow 15$

$l=-26 \rightarrow 26$

$w=1 /\left[\sigma^{2}\left(F_{o}^{2}\right)+(0.0679 P)^{2}\right]$
where $P=\left(F_{o}^{2}+2 F_{c}^{2}\right) / 3$

$(\Delta / \sigma)_{\max }<0.001$ 。

$\Delta \rho_{\max }=0.24{\mathrm{e} \AA^{-3}}^{-3}$

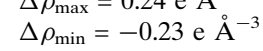

Extinction correction: SHELXTL

Extinction coefficient: 0.037 (4)
Table 2

Hydrogen-bond geometry $\left(\AA{ }^{\circ},{ }^{\circ}\right.$.

\begin{tabular}{lclll}
\hline$D-\mathrm{H} \cdots A$ & $D-\mathrm{H}$ & $\mathrm{H} \cdots A$ & $D \cdots A$ & $D-\mathrm{H} \cdots A$ \\
\hline $\mathrm{N} 1-\mathrm{H} 1 \mathrm{~N} \cdots \mathrm{O} 2^{\mathrm{i}}$ & $0.93(2)$ & $1.90(2)$ & $2.816(5)$ & $167(4)$ \\
$\mathrm{N} 2-\mathrm{H} 2 \mathrm{~N} \cdots \mathrm{O} 1$ & $0.91(2)$ & $1.90(2)$ & $2.795(5)$ & $168(4)$ \\
$\mathrm{N} 3-\mathrm{H} 3 \mathrm{~N} \cdots \mathrm{O} 3^{\text {ii }}$ & $0.89(2)$ & $1.95(3)$ & $2.806(5)$ & $161(4)$ \\
$\mathrm{N} 4-\mathrm{H} 4 \mathrm{~N} \cdots \mathrm{O} 4^{\text {iii }}$ & $0.90(2)$ & $1.89(2)$ & $2.783(5)$ & $174(5)$ \\
\hline \multicolumn{4}{l}{ Symmetry codes: (i) $x-1, y, z$; (ii) $x+\frac{1}{2},-y+\frac{1}{2},-z+1 ;$ (iii) $x-\frac{1}{2},-y+\frac{3}{2},-z+1}$.
\end{tabular}

SADABS (Sheldrick, 2003) was used to correct for the synchrotron beam decay through frame scaling. Methyl $\mathrm{H}$ atoms were positioned geometrically $(\mathrm{C}-\mathrm{H}=0.98 \AA)$ and refined as riding, with free rotation about the $\mathrm{C}-\mathrm{C}$ bond, and with $U_{\text {iso }}(\mathrm{H})$ values of $1.5 U_{\mathrm{eq}}(\mathrm{C})$. Ring-attached $\mathrm{H}$ atoms were also positioned geometrically $(\mathrm{C}-\mathrm{H}=$ $0.95 \AA$ ) and refined as riding, with $U_{\text {iso }}(\mathrm{H})$ values of $1.2 U_{\text {eq }}(\mathrm{C})$. Amide $\mathrm{H}$ atoms were found in a difference map and refined with $U_{\text {iso }}(\mathrm{H})$ values of $1.2 U_{\text {eq }}(\mathrm{N}) ; \mathrm{N}-\mathrm{H}$ bond lengths were restrained to 0.90 (2) $\AA$. In the absence of significant anomalous scattering effects, Friedel pairs were merged in the final refinement cycles.

Data collection: APEX2 (Bruker, 2004); cell refinement: SAINT (Bruker, 2004); data reduction: $S A I N T$; $\operatorname{program}(\mathrm{s})$ used to solve structure: SHELXTL (Sheldrick, 2001); program(s) used to refine structure: SHELXTL; molecular graphics: SHELXTL and MERCURY (Version 1.3; Bruno et al., 2002); software used to prepare material for publication: $S H E L X T L$ and local programs.

The authors thank Dr R. W. Harrington, Mr L. Russo and $\mathrm{Mr} \mathrm{Z}$. Yuan for assistance with data collection and processing as part of the EPSRC National X-ray Crystallography Service at Station 9.8, SRS, Daresbury, England. The authors also thank the EPSRC for funding and the CCLRC for synchrotron beam-time allocation.

Supplementary data for this paper are available from the IUCr electronic archives (Reference: HJ1052). Services for accessing these data are described at the back of the journal.

\section{References}

Beak, P. \& Covington, J. B. (1978). J. Am. Chem. Soc. 100, 3961-3963.

Beak, P., Covington, J. B. \& White, J. M. (1980). J. Org. Chem. 45, 1347-1353.

Beak, P., Fry, F. S., Lee, J. \& Steele, F. (1976). J. Am. Chem. Soc. 98, 171-179.

Bruker (2004). APEX2 and SAINT. Bruker AXS Inc., Madison, Wisconsin, USA.

Bruno, I. J., Cole, J. C., Edgington, P. R., Kessler, M., Macrae, C. F., McCabe, P., Pearson, J. \& Taylor, R. (2002). Acta Cryst. B58, 389-397.

Clegg, W. \& Nichol, G. S. (2004). Acta Cryst. E60, o1433-o1436.

Coburn, R. A. \& Dudek, G. O. (1968). J. Phys. Chem. 72, 1177-1181.

Gibson, J. A., Kynaston, W. \& Lindsey, A. S. (1955). J. Chem. Soc. pp. 43404344.

Katritzky, A. R., Rowe, J. D. \& Roy, S. K. (1967). J. Chem. Soc. B, pp. 758-761.

Kvick, A. (1976). Acta Cryst. B32, 220-224.

Kvick, A. \& Olovsson, I. (1969). Ark. Kemi, 30, 71-80.

Mason, S. F. (1957). J. Chem. Soc. pp. 4874-4880.

Parchment, O. G., Hillier, I. H. \& Green, D. S. V. (1991). J. Chem. Soc. Perkin Trans. 2, pp. 799-802.

Penfold, B. R. (1953). Acta Cryst. 6, 591-600.

Rawson, J. M. \& Winpenny, R. E. P. (1995). Coord. Chem. Rev. 139, 313-374.

Sheldrick, G. M. (2001). SHELXTL. Version 6. Bruker AXS Inc., Madison, Wisconsin, USA.

Sheldrick, G. M. (2003). SADABS. University of Göttingen, Germany.

Wong, M. W., Wiberg, K. B. \& Frisch, M. J. (1992). J. Am. Chem. Soc. 114, $1645-1652$. 